\title{
A Survey on the Status of Summer and Winter Camps in German Universities and Reflections
}

\author{
Tingting Ma, Wenfei Lin, Zixuan Han, Yuwei Wang \\ Faculty of Foreign Languages, East China University of Science and Technology, Shanghai, China \\ Email:2529430246@qq.com
}

How to cite this paper:Ma, T.T., Lin, W.F., Han, Z.X. and Wang, Y.W. (2021) A Survey on the Status of Summer and Winter Camps in German Universities and Reflections. Open Access Library Journal, 8: e7548. https://doi.org/10.4236/oalib.1107548

Received: May 19, 2021

Accepted: June 27, 2021

Published: June 30, 2021

Copyright $\odot 2021$ by author(s) and Open Access Library Inc.

This work is licensed under the Creative Commons Attribution International License (CC BY 4.0).

http://creativecommons.org/licenses/by/4.0/ (c) (i) Open Access

\begin{abstract}
German university summer and winter camps have many advantages with their relatively low course fees, abundant scholarships and beautiful natural environment. In this paper, through the survey of Chinese university students and the study of German university summer and winter camps, we summarize the characteristics of German university summer and winter camps with various themes, excellent location and reasonable curriculum. It also compares with the current status of summer and winter camps in Chinese colleges and universities, and puts forward the references of actualizing the theme, rationalizing the scale, diversifying the lectures, and transparent information management.
\end{abstract}

\section{Subject Areas \\ Culture, Higher Education}

\section{Keywords}

German Study Tour, Summer and Winter Camps, Education and Training

\section{1. 引言}

国际高校夏冬令营是一种教乐结合的假期游学课程, 让学生在感受名校 的课堂氛围和参加专业学术课程的同时体验国外的留学生活, 在短期留学项 目中越来越受到学生的关注, 拥有着不可忽视的地位, 其申请也在国内掀起 了一阵热潮。英美国家作为最受欢迎和最广为人知的留学目的国已经有相对 庞大数量的论文对其进行研究, 而德国相对英美的数据和资料较少, 人们对 其了解也大多很浅或者不全面, 之前关于这方面的研究也并没有专门涉及对 德国高校的系统分析。本论文研究是在问卷调查和数据分析的基础上进行的, 具有真实性和有效性, 意在让读者了解德国夏冬令营的教学现状和基本信息, 
同时为中国高校提供了进步思路, 为教育工作者给予一定的启示。

\section{2. 德国夏冬令营背后的中德对外交流基本国情}

\section{1. 中国教育对外合作交流近况}

根据《2020 中国留学白皮书》统计, 约有 89 万中国学生在海外留学。自 2016 年以来, 中国已成为世界最大留学人口输出国, 中国留学生的数量在一年 比一年地增加, 在各国际生中的占比也越来越高。而同样不可否认的, 中国的 经济及教育发展也与留学生的现状和未来留学的趋势息息相关。目前中外教育 的合作交流模式诸多, 有留学生交流, 如夏(冬)令营、体验跨文化游学和长期 留学等, 除此之外还有师资交流、科研合作、教育代表团和学者交流、中外合 作办学等项目。夏、冬令营就是其中一种性价比较高的选择, 为国内学生提供 了体验国际教育文化的平台, 在短期内收获一定的专业知识的同时作为跳板, 为有进一步留学意向的学生创造了有利的条件、提供了良好的考察体验机会。 相比较于前些年, 越来越多的人在长期留学前就会去丰富自己在国外学习的经 历, 更多的意向留学生会选择参加 “冬令营夏令营” “短期交换项目” “游学 营” 等等活动来积累海外学习的经验。通过这种方式有意向留学的学生也可以 在参加专业课程的同时借此熟悉留学环境, 体验原汁原味的德国大学生活。

\section{2. 德国高校留学现状}

德国高校与其他国家高校保持着大量的合作。这些合作协议促进了学生 和教授之间的学术交流, 同时也推动了联合科学项目的实施。然而, 目前在 各种科学领域开展新合作的潜力其实仍然很大。从全球范围来看, 德意志联 邦共和国目前仍旧是最具吸引力和最受留学生青崃的国家之一。德国的大学 是公认的强有力的合作伙伴, 特别是他们的创新潜力, 丰富的传统, 并且他 们对国际化的关注尤为突出。德国的高校系统极为多样化。多数大学由公共 资金资助, 并受联邦政府的监督。在 2019/20 年度的冬季学期, 德国大学注 册学习的人数达到了约 32 万, 相较于前一年新增了约 1.8 万名新生, 增长的 幅度达到了 $6 \%$ 。德国留学生的数量在近十年来一直在呈现着上涨的趋势, 这 也侧面表现了了德国作为留学国所具备的高教学质量和吸引力。德国学术交 流中心(DAAD)和德国高等教育与科学研究中心(DZHW)在最新发布的第 20 版《科学大都会 2020(Wissenschaft Weltoffen 2020)》一书中写到, 自 2010 年 以来, 国际学生的数量共增长了 $76 \%$ 。而德国许多高校为了吸引和招收国际 生也在原有的教学大纲和课程设置基础上进行了一些改进, 有些专业为此开 设了用英语或英、德双语授课的国际课程。夏冬令营就是一个很好的例子, 它作为德国短期留学课程是德国各大学正在积极推广的一项假期授课项目, 目的在于让各国优秀的青年大学生在大学课堂里亲身体验德国高等教育, 在 学习专业知识的同时也了解德国这个国家。

\section{3. 德国夏冬令营的概况}

\section{1. 目标群体}

德国夏冬令营的主要目标人群是高校学生。以城市风貌考察研究和德语 
学习为主题的文化交流类项目对申请者的主修专业没有严格限制。以人文学 科背景中的论题, 如犹太文化、欧洲政治、电影、宗教、哲学为主题的项目 则要求申请者需要对主题有兴趣了解或是能初步了解和课程主题相关知识。 理工相关的假期项目如建筑设计、程序设计、通信工程、机器人技术要求相 关学生必须具有专业背景。一些进阶课程只接受本科高年级学生以及硕士、 博士和从业人员的申请。如果假期学校包含了相关的实习项目, 则会要求申 请者必须年满十八周岁。商科类项目通常要求申请者具有相关学科背景。艺 术类项目需要申请者掌握专业技能。2021 年, 在新型冠状病毒疫情的影响下, 德国大学仍然提供了近 160 多个假期学校项目。纵览概况, 德国夏冬令营为 来自不同国家、不同专业的高校学生提供了丰富且个性化的选择。

\section{2. 教学安排}

以 2021 年 DAAD 页面提供的假期学校信息为基础计算, 大多数德国夏 冬令营项目的持续时间为四周, 平均周学时约 25 小时。班均人数在主要在 18 30人之间。前两周学校会提供语言和专业基础课, 后两周会进行专业进 阶课、学习成果展示、实习、结业考试等。以 “短学期” 为主题的假期课程 会提供不同类型的学分课供学生修读, 学程设置更接近一般的大学课程安排。 受疫情影响, 线上的假期课程也逐渐增多。此类课程学程较长, 使学生能在 更宽松的时间范围内借助线上课程灵活学习。

\section{3. 申请要求}

\subsection{1. 语言}

所有的夏冬令营都要求非本国申请者具备一定的外语交流能力(如图 1)。 大多数暑期项目需要申请人有最低达到英语 $\mathrm{B} 1$ 的语言能力。在与德国文化、 商业强相关的项目中, 申请人至少应该达到德语 B2 C2 的语言水平。在大多

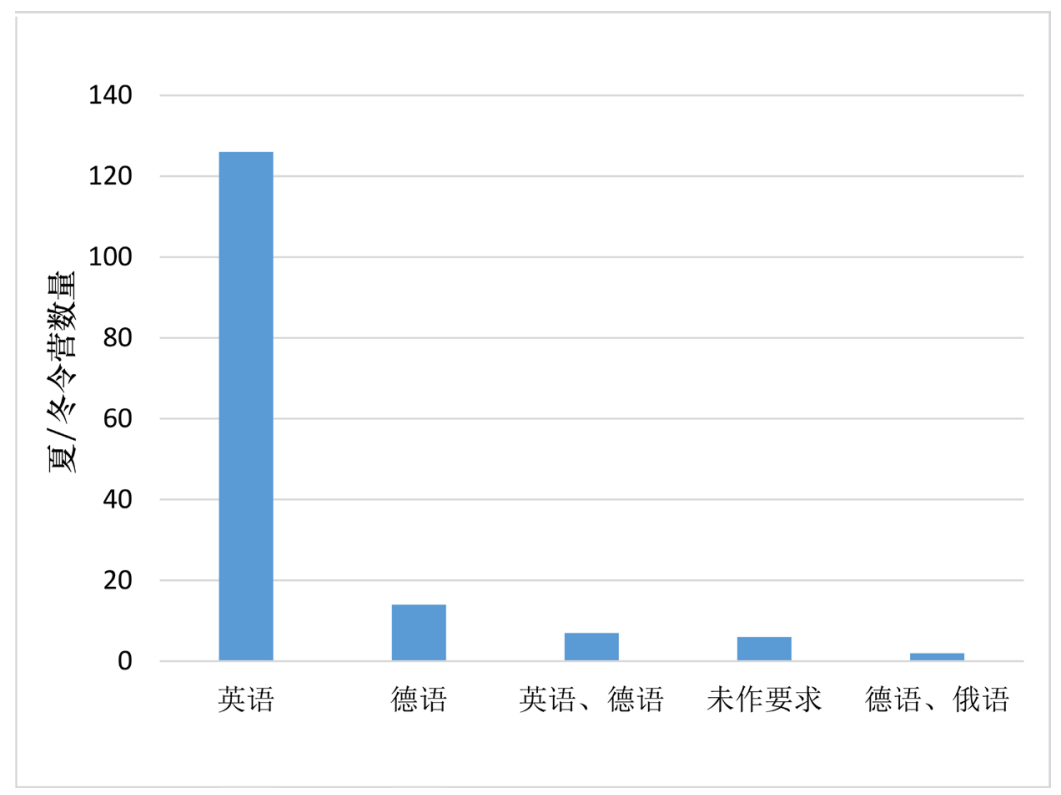

图 1. 2021 德国夏冬令营授课语言状况 
数假期课程中, 学生只需要具备英语能力即可。因此, 对中国本科学生而言, 他们无需担忧在德国夏冬令营中因为不会德语而无法参加项目。

对于平均四周的课程时间, 文化研究类课程所需费用在 650 1100 欧元之 间。商科、法律课程与部分工科课程费用在 1200 2800 欧元之间。和欧美国 家相比, 文化研究类课程的价格优势明显。在一些课程中, 此类收费还包含 了住宿和活动费用。DAAD 也会对部分课程的申请者进行资助, 但是申请者 必须进行两个学年的大学学习并且选择德语授课的项目。

\subsection{2. 申请时间}

如果学生想要申请受资助的夏冬令营, 应该从年末开始在 DAAD 官网上 搜索相关项目信息，并在官网提示的截止日期(通常是 12.31)之前提交申请。 各大学提供的项目申请截止日不同, 但通常在每年六月份之后, 暑期课程的 注册截止。每年九月份后, 冬季课程的注册截止。如果在递交申请后学校无 法提供足够的位置, 那么学生将被安排至等候名单中, 直到有学生放弃申请 机会顺延为止。

\section{4. 德国夏冬令营申请渠道}

如果德国高校和中国高校之间有合作关系, 那么学生可以从中国高校教 务处网站中获得德国夏冬令营信息并进行申请。其他学生可以借助 DAAD 等 德国学术交流机构网站查找信息, 通过邮件与高校联系并申请假期课程。通 过对上海高校本科学生的调查, 在 1423 份有效问卷中, $71.75 \%$ 的学生曾通过 本校网站和相关讲座获得德国夏冬令营的信息。相比之下，只有 $43.43 \%$ 的学 生主动浏览德国高校网页来寻找合适的假期项目。在参加德国夏冬令营之前, $67.81 \%$ 的学生没有了解过德国的假期项目。因此, 虽然德国夏冬令营有着成 熟的自主申请渠道, 本科学生仍然因为对德国假期项目的不了解而较为依赖 高校合作获得德国夏冬令营申请渠道的相关信息。

\section{4. 中德两国高校夏冬令营比较}

中国高校夏冬令营按照目的可以主要分为两类，第一类是保研夏令营， 为了更客观选拔全面优秀的硕士研究生; 第二类为学术交流夏冬令营, 旨在 各地学者对某一主题进行学习交流。此文中讨论的为中国高校第二类夏冬令 营与德国高校夏冬令营的比较以及带给中国高校的启示。

\section{1. 主题设置}

在我们研究调查的一百余个德国高校夏冬令营中, 主题丰富多彩, 从历 史人文跨越到工业 4.0, 从欧洲艺术跨越到国际贸易; 主题繁多且涉足了各个 领域, 且大部分主题深刻富有内涵, 具有国际化视野: 如柏林洪堡大学 2021 年开设的 “德国的犹太叙事-探索过去和现在的记忆” 主题夏令营以及柏林 自由大学开设的 “全球挑战-可持续的未来” 主题夏令营。这些体现了德国教 育中对于历史的反思以及对于全球化的重视。而中国更多则侧重于针对某一 领域的掌握或针对性提高某一方面的技能：如 “高级英语听力能力培训”、 
“传感器技术及应用实践” 等等, 相对于德国高校夏冬令营的主题设置, 中 国高校的主题设置更偏向于实践、更具有针对性，同时也稍欠缺国际化视野， 略微缺乏深度思考。

\section{2. 时间安排}

德国高校夏冬令营时长从 1 周到 12 周不等, 且时间跨度也较大, 比较灵 活; 如柏林洪堡大学就提供 11 天、 15 天、 25 天和 28 天等数种时长不同的夏 令营; 弗莱堡大学开设的 “生物医学科学冬令营” 时间从 2020 年 11 月跨度 到 2021 年 4 月。而中国高校夏冬令营时间由于学期学制设置的原因, 主要集 中在 7 月和 8 月。

\section{3. 课程设置及授课方式}

大部分中德高校都会聘请对其夏令营课题具有一定权威性的老师与专家 进行开课讲座。中德高校都会开展关于其主题的课程导论、专业领域课程等 等, 开设的课程种类都比较丰富, 能满足大部分参与人群的需要; 但德国高 校更多地将课程重心放在研讨课上, 授课形式为互动授课, 包含小组讨论、 课题研讨等; 中国主要还是以教师授课的方式为主。

\section{4. 收费情况}

中国大部分高校所开设的夏冬令营寒暑期学校及寒暑期国际化课程, 对 注册学生均为免费开放, 如北京大学 2017 及 2018 年的夏令营。学员除了按 年度向学校缴纳学费外, 不需要额外缴纳夏令营暑期课程学习费用。授课期 间所发生的外聘教师国际旅费、住宿费、授课费等费用, 均由相关项目进行 支撑, 参与人员的食宿交通费用需要自理。而德国高校大部分夏冬令营课程 都为收费课程, 除去部分线上课程外, 且极大一部分德国高校的收费中除去 课程费还包含了活动费用: 如参观博物馆、鉴赏音乐会等费用。还有一部分 德国高校安排住宿, 住宿费因住宿条件不同而不同。总的来看, 由于中德经 济水平和社会发展的情况不同, 中国夏冬令营费用相对德国较低, 更偏向公 益性质, 但德国高校夏冬令营和其他欧美国家高校夏冬令营相比也是性价比 极高的选择。

\section{5. 德国夏冬令营突出特点以及对于留学的重要意义}

\section{1. 德国夏冬令营突出特点}

\subsection{1. 选择多样化}

德国夏校为想要前来短期留学的学生提供了丰富的选择空间, 不同的大 学其主题涵盖的范围十分广阔, 从专业领域的知识到兴趣方面的拓展都有涉 猎。在 DAAD(德国学术交流中心)的网站信息中可以看到德国各个大学紧跟 时事和需要开设的多种主题, 有从文化历史到科学机械, 从企业文化到社会 关注点, 从商业金融到创业形势等等, 学生们可以根据自己的专业或者兴趣 来选择相应的课程进行深入的了解。而即使是同一所大学也会有不一样的课 程供学生进行挑选, 比如柏林洪堡大学在 2020/2021 的短期课程中, 既有关 
于 “欧盟的危机和未来” 的政治性主题, 也有关于 “柏林墙与冷战时代” 的 历史性主题等等。而德国夏校的选择之所以具有多样性的特点, 有一定的原 因是因为他们的受众人群广泛, 不仅限于相关专业的本科生才能参加, 也鼓 励同学根据自己的兴趣来报名。

\subsection{2. 自然和人文环境占优势}

在上百份针对参加过国际留学项目的同学的问卷调查中我们发现, 德国 高校良好的自然和人文环境是受学生满意程度最高的两项。德国的高等院校 大部分坐落在人文环境良好、自然环境优美的城市, 如柏林、慕尼黑、海德 堡和法兰克福等等。高素质的教学水平、精密的科研设备和人性化的生活设 施也在客观条件和物质要求上为学生顺利完成本科学业给予了保障。德国许 多大学均有数百年的历史, 文化底蕴十分深厚。以创办于 1810 年的柏林洪堡 大学为例, 它是这座城市最古老的大学, 坐落于柏林市中心的菩提树下大道 街道上, 学校不设围墙, 对外也是呈开放状态, 具有古朴气息的校园建筑与 整座城市融为一体, 附近有著名的勃兰登堡门和博物馆岛, 都是各具特色的 优秀历史建筑。柏林洪堡大学的创校者威廉. 冯.洪堡作为德国著名的教育改革 家赋予了这所新制大学 “研究教学合一” 的新理念, 作为世界上第一所具有 现代意义的大学, 在二战前它可以说是德国最高学府和世界学术中心, 并在 两百多年的时间里孕育了 57 个诺贝尔奖获得者, 这样悠久和辉煌的历史无疑 为学校更增添了浓厚的人文色彩。

\subsection{3. 课程设置安排科学合理}

德国夏校在为学生提供丰富主题选择的同时, 也会针对相应课程提前为 学生介绍一些基本信息, 以及总体教学安排, 这些都可以在官方的相关留学 网站上清晰地了解到。我们在 DAAD 网站中总结了 2020/2021 年度德国 159 所大学短期课程(包括语言类课程和专业类课程)的概貌, 其中目标夏校的持 续时间、报名条件、教学使用语言、课程费用及其具体包含对象和学分转换 等基本信息都会在概况中一一列出。除此以外, 学生也可以从中直接获取对 应相关主题的学习内容和课程设置, 如每周上课的平均时长、每个小组/课程 平均参与人数等教学安排, 这些背景了解可以帮助学生对不同大学进行比较 和衡量从而选出最适合自己的课程。而根据我们的问卷调查显示, 课程内容 在学生参加夏令营过程中满意点中排在第三位(前两位分别是人文和自然环 境)。德国夏校的课程设置安排科学合理, 是在于它不只是一味地在课堂上进 行单一且单向的输出授课, 而是设置了讲座课、讨论课和参观游学等多元化 的教学形式, 在保证有师生之间有生动的课堂交流和互动教学的同时, 也会 走到课堂以外的地方, 让学生们通过亲身的实践体验从而更深入地掌握知识, 提升了学生在课堂中的主动参与度, 那么学生们自然也不会因为一味在教室 里面对白纸黑字而觉得课程枯燥乏味。

\section{2. 德国高校夏冬令营对于留学德国的重要意义}

\subsection{1. 德国高校国际教育概况}

德国是一个科技经济高度发达的传统强国, 工业实力雄厚, 是欧洲政治、 
经济、教育、文化中心, 尤其在机械制造、电气工程及自动化、化工制药等 领域, 在国际上享有很高的声誉, 属于世界顶尖水平。德国高校整体教育水 平高, 与其它欧美国家相比, 留学德国所需的费用低廉, 文凭含金量高, 就 业前景好。

21 世纪初期以来, 德国政府制定了适应国际留学市场激烈竞争的留学政 策, 实施了一系列高校国际教育改革, 加快高等教育国际化进程。随着联邦 政府多边化合作性措施的实行, 国际化教育策略的制定, 以及宽松的留学移 民政策的出台, 德国近二十年来国际教育发展迅速, 留学生人数连年攀升, 德国已成为欧洲最大留学输出国。[1]与此同时, 随着中德两国贸易往来的不 断深化, 中德双方在众多行业领域的合作不断加强, 赴德留学的中国学生数 量也展现出逐年增长的趋势。根据留德德意志学术交流中心和德国高等教育 与科学研究中心共同发布的《科学大都会 $2020 》$ 报告, 我国 2019 年赴德国留 学的学生数为 39,871 人, 占外国留学生总数 $13.2 \%$, 每年赴德留学人数平均 增长率达 $8.4 \%$, 中国已成为德国第一大留学生来源国

\subsection{2. 德国夏冬令营对于长期留学德国的参考意义}

夏冬令营作为短期留学的一种重要模式, 虽然周期较短, 但也为广大中 国学生提供了体验德国办学模式、专业课程、语言环境和文化环境的平台, 不仅性价比较高, 还能作为参加德国长期留学项目的重要跳板, 为有赴德留 学意向的学生提供重要的考察机会。

\section{1) 体验语言环境提高德语水平}

按照德国高校的要求, 学生须通过德国驻华使馆文化处留德人员审核部 (APS)的审核, 才能向德国高校递交申请, 国内申请人需递交学历等材料并参 加审核面谈或 TestAS 测试。赴德留学的学生需掌握扎实的德语基础知识并具 备一定的听说读写能力, 须通过德语语言考试方能申请入学。据统计, APS 面试审核通过率不足 30\%, 其主要原因为德语语言运用能力不足及德国文学 历史相关知识欠缺。[2]即使对一些本科为德语专业的学生来说, 因为国内大 学的课程学习缺乏语言环境, 德语实践应用机会较少, 口语能力也可能相对 较为薄弱。

德国夏冬令营无疑是一个提供语言环境和语言运用机会的良好平台, 除 了符合夏冬令营主题的专业课程外, 部分高校还会为基础较弱或零基础学生 专门提供德语语言课程, 以帮助他们提高德语语言水平。除此之外, 大部分 夏冬令营课程都设置有丰富的小组讨论、参观访谈等实践活动, 能为语言水 平提升提供较大的帮助。

\section{2) 体验高校课程获得专业技能}

我国学生赴德留学所学的专业统计占比: 工程科学约为 $42 \%$; 经济学、 社会科学和法学约为 $20 \%$; 数学、自然科学约为 $17 \%$; 语言学、文化学和体 育约占 $12 \%$; 艺术类专业约占 $5 \%$; 医学、健康学约为 $2 \%$; 农业、林业、营 养学、兽医约为 $2 \%$ (如图 2)。

根据 DAAD 网站上的信息, 2020 年和 2021 年德国高校夏、冬令营约有 $25 \%$ 与工程科学有关, $22 \%$ 为语言学、文化学, $43 \%$ 与经济学、社会科学和法 


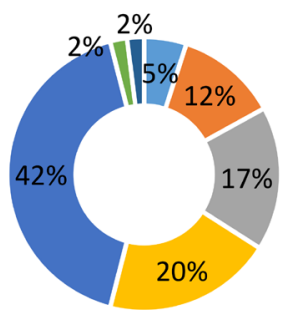

- 艺术类专业

- 语言学、文化学和体育

- 数学、自然科学

- 经济学、社会科学和法学

- 工程科学

口医学、健康学

- 农业、林业、营养学、兽医

图 2. 中国学生赴德留学所学专业

学有关, $3 \%$ 与数学和自然科学有关, $4 \%$ 为艺术类, $2 \%$ 为医学、健康学, 1\%属于农业、林业、营养学、兽医类。(如图 3)德国高校夏冬令营的主题丰 富新颖, 课程设置基本能满足我国留学生未来选择专业的需求, 与我国赴德 留学所学专业基本对应。对于有留德意愿的学生来说, 夏冬令营是体验德国 高校课程的最直接和最便捷的途径, 能收获一定的专业知识技能, 有利于规 划未来长期留学计划。

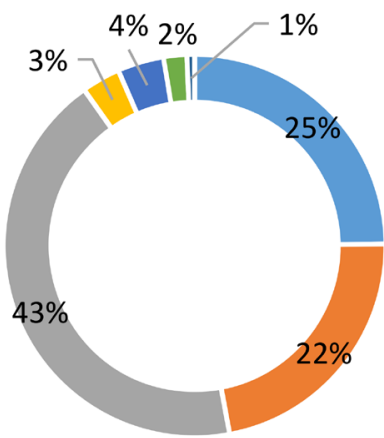

- 工程科学

- 语言学、文化学和体育

- 经济学、社会科学和法学 - 数学和自然科学

- 艺术学

- 医学、健康学

- 农业、林业、营养学、兽医

图 3. 德国 2020-2021 夏冬令营学科统计

\section{3) 适应教学模式树立留学信心}

德国高校的类型主要有: (1) 综合大学: 重在系统传授理论知识和学术方 法, 往往将科研与教学结合起来, 培养具有独立研究能力的科学人才; (2) 应 用科技大学: 重在实践与教学的紧密结合, 除了培养学生必要的专业理论知 识外, 还注重培养学生对于知识的实际应用; (3) 艺术、电影和音乐学院: 培 养发展学生的艺术才能。

德国高校的教学模式注重于学生的学习主动性, 设置有讲课、练习课、 研讨论和实习课。讲课即由教授或讲师对专业课程进行讲解, 类似于我国高 校的课堂教学。练习课是基础阶段的一种课程类型, 学生通过完成作业对所 学知识进行练习。研讨课在德国高校教学环节中有着至关重要的作用, 通过 讨论培养学生独立思考和表达观点的能力。实习课也是德国高校教学中重要 的一环, 尤其对于工程科学类的专业, 重点提升学生的实践能力。[3]

夏冬令营的课程设置与德国高校教学极为相似, 除了教授和讲师的讲座 
和专业课程、练习课程之外, 德国高校夏冬令营还设置了研讨课, 组织学生 进行小组讨论、课题研讨等互动环节, 注重培养学生独立思考能力, 提升学 习积极性, 锻炼学生的观点表达能, 部分项目还包括实习环节。因此参加德 国高校夏冬令营能帮助我国学生感受其教学模式, 适应其教学活动的方式, 跳出固有的思维模式, 为未来留学树立信心。

\section{4) 体验文化生活提高适应能力}

出国留学对于很多学生来说是不小的挑战, 学生不仅需要培养自己独立 生活的能力, 克服语言和专业课程上的难关, 更需要让自己了解当地的文化 生活, 努力融入学校和社会生活, 才能让自己的留学进程更为顺利。夏冬令 营作为短期留学项目, 为留学生提供了重要的缓冲地带, 学生不仅有机会体 验德国的文化生活, 适应中德文化差异, 还能提高自己独立生活的能力, 有 利于为未来长期留学做好心理准备。

\section{6. 德国高校夏冬令营带来的启示与思考}

\section{1. 结合本国国情及世界发展, 开设紧跟时事与局势的主题}

中国高校夏冬令营目前开设的主题大多不够具有国际化视野, 可以适当 开设一些紧扣时事、针对全球化的主题, 如北京大学中国教育财政科学研究 所与世界银行和俄罗斯高等经济大学教育研究所于 2017 年联合举办 “教育 与发展” 的国际夏令营就是一个正面的例子。这样类似的主题可以引发参与 者的深度思考, 使他们具有更开阔更深遂的国际化视野, 从而更容易同国际 接轨。同时开设这样的主题更容易吸引全球各地的学者, 给其他国家地区提 供丰富的参考, 分享普世的经验。

\section{2. 优化夏冬令营的时长与规模}

在我们调查的数百位参与过中国高校夏冬令营的人员中, 有接近一半的 人群认为夏冬令营 3-7 天的时长对他们而言显得略微过短, 没能更深入探讨 主题并充分开展各项活动, 与其他同伴以及教师的交流也不够深入。但从主 办方的角度来看, 参与者人数越多, 时间越长, 活动管理难度就越大, 不安 全不可控因素就越多。因此, 主办方在确定夏冬令营的规模与时长之前应当 多方面广维度去考量影响因素: 如果以扩大影响为主要目的, 则保持较大招 生规模, 同时控制好活动时间, 认真篎选相关活动; 如果以深入学术研究为 主要目的, 则控制整体招生规模, 适当延长举办时间, 做好前期策划。

\section{3. 将授课形式多样化, 提升学员课堂参与度}

中国高校夏冬令营授课形式大多为教师单向讲授, 这样的授课形式对参 与者而言显得有些单调与枯燥, 同时参与者不能够及时地了解自己知识的欠 缺与实践能力的不足。因而中国高校也可效仿德国高校开设一些研讨课, 采 用启发式教学, 提升学员的语言表达能力, 尤其是针对想提升中文水平的国 际学员而言, 这样既提升了学员的自信心, 又转变了传统的教学模式, 同时 对教师教学模式也是一种创新, 增进各个个体的互动、沟通与交流。[4] 


\section{4. 促进信息与管理更加透明化与系统化}

德国高校夏冬令营的规模较大, 开设的课程也名目繁多, 同时学生来自 世界各地, 背景各不相同。但 $\mathrm{DAAD}$ (德国学术交流中心)官网上可以根据需 求搜索出各类德国高校夏冬令营信息, 地点、费用、时长、活动内容等等一 目了然。学员可以通过网络进行注册、报名、缴费、退费等等一系列操作。 同时如果有其他疑问还可以直接联系到高校发邮件进行提问。中国高校夏冬 令营官方信息只能通过高校官网查询, 且容易被不良中介机构钻空子, 但在 德国高校绝大部分夏冬令营是不需要中介的, 可以自己报名申请, 如有合作 机构也会在各类学术交流网站上以及学校官网上公布, 避免不法中介钻空子。 同时各高校可以成立管理夏冬令营的小组或者办公室, 已有的可将其更为规 范化, 将各人员的职责更为明确化, 以免出现由于人员混乱而造成的工作不 到位: 如负责回答咨询的人员、负责联系安顿外聘教师的人员、负责经费管 理的人员等等, 要分工明确到位, 以便统筹策划协调各项事宜。[5]

\section{7. 结论}

本研究表明, 德国夏冬令营是具有较强实践性、较高学术水平的留学体 验平台, 对于长期留学和我国提高教育对外开放水平, 优化夏冬令营模式有 着重要的参考价值。本文研究了德国夏冬令营的现状及其对于我国教育对外 开放的参考意义, 开展了有关德国夏、冬令营的基本信息的全方位调查, 梳 理了当下中德两国教育对外交流的基本情况, 对中德夏令营进行对比, 进一 步总结得出德国短期游学项目主题多样、自然人文环境优势、课程设置合理 等特点, 分析指出参加德国短期留学项目对于我国有留德意向学生体验语言 环境和高校课程, 提高德语水平并获得专业技能, 以及适应教学模式、树立 留学信心, 体验文化生活、提高适应能力有着重要的积极意义。分析得出德 国夏冬令营的模式对我国夏冬令营未来发展的启示: 应进一步贴合世界时事、 结合本国国情, 合理设置时长与规模, 采取多样化形式教学、提升学员课堂 参与度, 将信息与管理更加透明化与系统化。

\section{基金项目}

华东理工大学大学生创新创业项目 “德国高校夏令营和冬令营现状调 查” (项目编号: X20299)。

\section{Conflicts of Interest}

The authors declare no conflicts of interest regarding the publication of this paper.

\section{References}

[1] 任平, 文雯, 贺阳. 德国近二十年高校国际学生教育: 发展现状、动因及启示[J]. 高教探索, 2019(10): 36-43.

[2] 王博. 德国自费留学情况调查研究的几点建议 [J]. 传播力研究, 2020, 4(18): 189-190. 
[3] 陈蓓. 浅谈德国的高等教育体制和留学德国的政策及优势 [J]. 科技信息(科学教 研), 2007(20): 129+142.

[4] 胡莉芳, 郝英. 研究型大学暑期学校: 开放、国际、市场[J]. 国家教育行政学院学 报, 2011(4): 23 .

[5] 周游. 关于当代中国高校举办国际暑期学校的若干思考 [J]. 高教学刊, 2016(8): 26-27.

\section{Appendix (Abstract and Keywords in Chinese) 德国高校夏令营及冬令营现状调查及思考}

摘 要: 本文通过对中国高校学生的调查和德国高校夏、冬令营的考察研究, 通过问卷调查和访谈等研究方法, 通过大规模数据收集总结出德国高校夏冬 令营主题多样、区位优异、课程设置合理的特点。并与中国目前高校的夏冬 令营现状对比，提出主题实事化、规模合理化、授课多样化、信息管理透明 化的参考意见。

关键词: 德国游学、夏冬令营、教育培养 